\title{
VARIAÇÃO DO ÍNDICE DE VEGETAÇÃO POR DIFERENÇA NORMALIZADA NA LAGOA ITAPEVA, LITORAL NORTE DO RIO GRANDE DO SUL, BRASIL, A PARTIR DE ANÁLISE DE SÉRIES TEMPORAIS
}

\section{Variations of the Normalized Difference Vegetation Index (NDVI) in the Itapeva-RS Lake, north coast of Rio Grande do Sul, Brazil, from Temporal Series Analysis}

Juliane Beatriz Lissner

Mestre em Geografia, UFRGS

jujub185@yahoo.com.br

Laurindo Antonio Guasselli Prof. Adjunto, Instituto de Geociências / Programa de Pós-graduação em Geografia, UFRGS laurindo.guasselli@ufgrs.com.br

Artigo recebido em 11/10/2011 e aceito para publicação em 18/03/2013

Resumo: O objetivo do trabalho foi analisar os padrões de comportamento espaço-temporal dos valores do Índice de Vegetação por Diferença Normalizada (NDVI) na lagoa Itapeva-RS, por meio de imagens Landsat TM5 e ETM+7, compreendendo o período de 1985 a 2010. Para a análise do comportamento espaço-temporal foram utilizadas classes de Índice de Vegetação por Diferença Normalizada (NDVI) e Análise por Séries Temporais (TSA) de imagens. Para validação dos padrões observados foram coletadas amostras de água em seis pontos na lagoa Itapeva para clorofila_a, Totais de Sólidos Suspensos e transparência do disco Secchi. Estes resultados foram correlacionados com os valores de NDVI. Os mapas de classes de NDVI gerados após a análise da TSA evidenciaram padrões de dinâmica espaciais e sazonais associados as variáveis ambientais atuantes, permitindo o estabelecimento de três grandes compartimentos para a lagoa Itapeva: norte, centro e sul. A análise da série temporal de imagens mostra que o aumento e o decréscimo dos valores de NDVI estão associados aos períodos de floração do fitoplâncton. Concluiu-se que a análise da Série Temporal de imagens Landsat foi satisfatória no que se refere ao comportamento espaço-temporal da variação das classes de NDVI.

Palavras-chave: NDVI, Análise de Séries Temporais, Lagoa Itapeva.

Abstract: The objective of this study was to analyze the pattern spatial-temporal values of the Normalized Difference Vegetation Index (NDVI) in Itapeva-RS lake, using Landsat TM5 and ETM + 7 images, from 1985 through 2010. For the analysis of space-temporal behavior classes was used Normalized Difference Vegetation Index (NDVI) classes and Temporal Series Analysis (TSA). To validate the observed patterns were collected water samples from six points in the Itapeva Lake for clorofila_a, Total suspended solids and Secchi disk transparency. These results were correlated with NDVI values. The NDVI classes maps generated after analysis of TSA, showed dynamic patterns of seasonal and spatial associated with environmental variables that were actuating, allowing the establishment of three distinctive surfaces in Itapeva Lake: north, center and south. The Temporal Series Analysis of images shows that the increase and decrease of NDVI values are associated with periods of phytoplankton bloom. One concluded that the Temporal Series Analysis of Landsat images was satisfactory with regard to the behavior of spatial and temporal variation of NDVI classes.

Key-words: NDVI, Time Series Analysis, Itapeva Lake. 


\section{INTRODUÇÃO}

A necessidade de monitoramento contínuo e do manejo adequado dos recursos hídricos torna necessária a busca de métodos de pesquisa inovadores e eficientes que proporcionem o acompanhamento de forma prática e de longa duração. A demanda crescente pelo uso de técnicas de geoprocessamento e sensoriamento remoto na análise de parâmetros de qualidade da água amplia e agiliza essas possibilidades de gestão dos recursos hídricos. Mesmo assim, de acordo com Londe et al (2005), há poucos estudos voltados para a aplicação de técnicas de sensoriamento remoto em águas interiores, comparando-se a outros ecossistemas.

Estudos que integram ferramentas de sensoriamento remoto e de análise de séries temporais de imagens de satélite mostram-se extremamente úteis para a compreensão da evolução ambiental devido a disponibilidade de dados e de imagens facilitando o monitoramento espacial e temporal de parâmetros de qualidade de água.

O comportamento espectral da água e o comportamento espectral da clorofila_a em ambientes naturais são componentes muito importantes a serem analisados em termos de qualidade de água quando se busca compreender os processos de evolução e dinâmica dos corpos de água.

No que se refere ao comportamento espectral da água, a luz que incide sobre um ambiente aquático se atenua rapidamente, isto é, é absorvida e espalhada pelos componentes da água. O que se observa através dos sensores remotos é a radiância emergente captada pelo sensor, resultante do espalhamento causado pelo material em suspensão na zona eufótica, conforme Pereira (1993).

A água possui comportamento espectral distinto de acordo com seu estado físico; líquida, sólida ou gasosa (Figura 1). A água em estado líquido apresenta baixa reflectância, em torno de $10 \%$, em comprimentos de onda na faixa do visível (entre $0,38-0,7 \mu \mathrm{m}$ ). Nas demais regiões do espectro eletromagnético ocorre a absorção da radiação incidente.

Desta forma, os estudos da qualidade da água em corpos hídricos são limitados às bandas espectrais do visível, região que ocorre os principais picos de reflectância da água, e no infravermelho próximo.

Figura 1. Comportamento espectral da água em diferentes estados físicos.

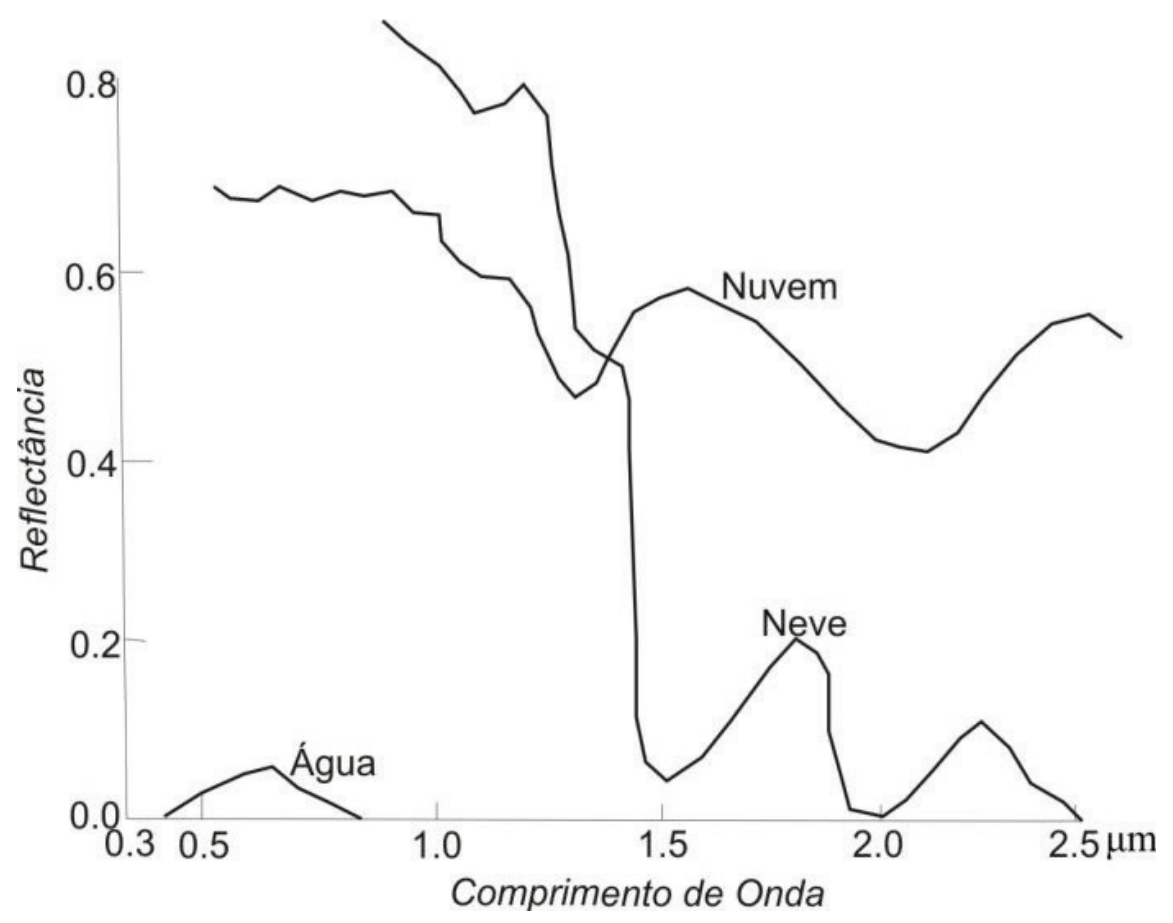

Fonte: Adaptado de Novo (1998) apud Bowker et al (1985). 
Todo corpo hídrico apresenta certa quantidade de sedimentos em suspensão, e a resposta espectral da água está diretamente associada a estes COAs (Componentes Opticamente Ativos), que são representados pelos sedimentos inorgânicos (areia e silte) e sedimentos orgânicos (organismos fitoplanctônicos). Os sedimentos inorgânicos são os maiores responsáveis pelo espalhamento da luz incidente na água, e em segundo lugar os sedimentos orgânicos, mais especificamente o fitoplâncton.

Outra técnica de sensoriamento remoto utilizada para a avaliação da qualidade da água e monitoramento de recursos hídricos é detecção de clorofila-a como parâmetro de quantificação de biomassa (Londe et al, 2005). De acordo com Arraut et al (2005), o fitoplâncton é um grupo heterogêneo composto principalmente por algas fotossintetizantes que se distribuem por grande parte dos ambientes marinhos e aquáticos continentais pelo mundo.
No que se refere aos pigmentos fitoplanctônicos, há uma variedade significativa dentro de um corpo de água. Alguns exemplos de pigmentos fotossintetizantes são as clorofilas a, b, e c e os carotenóides, no entanto, o principal responsável pela absorção de energia luminosa é a clorofila.

A interpretação dos espectros de reflectância e absorção da água e de seus componentes opticamente ativos servem como base para a avaliação e monitoramento do estado trófico de ambientes lênticos utilizando-se apenas métodos de sensoriamento remoto. Desta forma, passam a se estabelecer relações entre a concentração de clorofila e a resposta espectral obtida pelo satélite.

A clorofila-a possui dois picos de absorção, uma no azul em $0,433 \mu \mathrm{m}$ e outro no vermelho em 0,686 $\mu \mathrm{m}$, conforme Londe et al (2005), Figura 2.

Figura 2. Influência da clorofila e da matéria orgânica na reflectância da água.

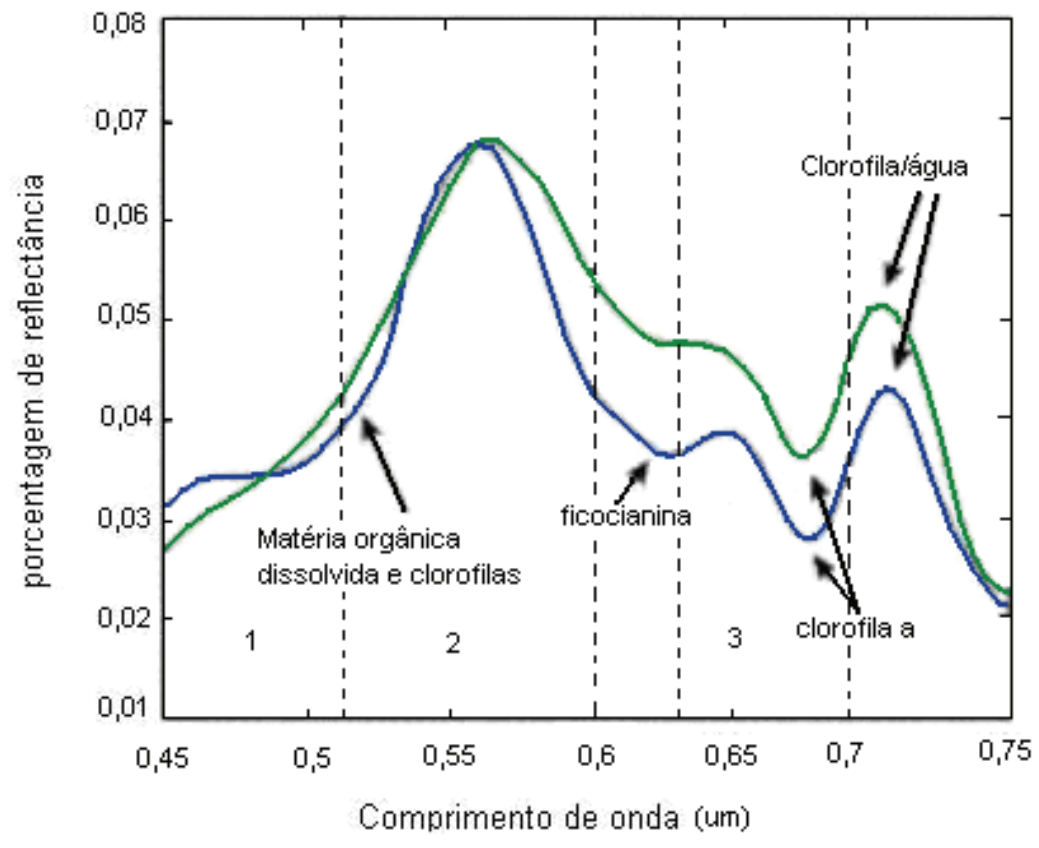

Fonte: Londe et al (2005).

A interpretação dos espectros de reflectância e absorção de clorofila_a possibilitam, através da utilização de técnicas de sensoriamento remoto e de ferramentas como o Índice de Vegetação por Diferença Normalizada (NDVI), estabelecer relações entre a concentração de clorofila e a resposta espectral obtida pelo satélite.

A Planície Costeira do Rio Grande do Sul, segundo Tomazelli (1990) e Tomazelli \& Villwock (1991), é constituída por um conjunto complexo de 
ambiente e sub-ambientes incluindo um grande conjunto de corpos aquáticos costeiros (lagoas e lagunas). Dado a importância ambiental das características ecológicas associadas aos ambientes úmidos, são poucos os estudos realizados nessas lagoas, articulando parâmetros de qualidade da água e sensoriamento remoto com vistas ao entendimento de sua dinâmica.

Neste sentido, o presente estudo analisa a "variação do Índice de Vegetação por Diferença Normalizada na lagoa Itapeva, litoral norte do Rio Grande do Sul, Brasil, a partir de análise de séries temporais". Busca entender a dinâmica da distribuição do NDVI na lagoa a partir dos parâmetros de Totais de Sólidos em Suspensão e em especial o parâmetro clorofila com base em aplicação de técnicas de sensoriamento remoto.

\section{ÁREA DE ESTUDO, LAGOA ITAPEVA}

A lagoa Itapeva localiza-se no Litoral Norte do Rio Grande do Sul. Essa região tem como limites o Oceano Atlântico a leste e a encosta da Serra Geral a oeste e, no sentido norte-sul estende-se de Torres até Osório. "As coordenadas dos pontos extremos da lagoa são $50^{\circ} 01^{\prime} 50.76$ " O, 29³6'16.58" S e 4947'33.98" O, 29²2'14.36” S, Figura 3.

Villwock \& Tomazelli (1991) analisaram os processos de sedimentação, padrões morfológicos e distribuição dos sedimentos assim como o processo evolutivo e formação do sistema lagunar da Planície Costeira do Rio Grande do Sul. A lagoa Itapeva encontra-se sob o domínio dos sedimentos costeiros, cuja superfície tem elevada permeabilidade, o que facilita a recarga dos aqüíferos livres. O sedimento é essencialmente arenoso, incluindo horizontes de conchas calcárias que podem influenciar na composição química da água subterrânea.

Conforme estudos de Lopardo (2002), a área total corresponde a $124,75 \mathrm{~km}^{2}$, e um volume de 245,5 x $10^{6} \mathrm{~m}^{3}$, e profundidades médias em torno de 2,23 metros e máximas de 3,5 metros. Em relação ao seu eixo longitudinal, segundo Cardoso (2001), chega a aproximadamente $31 \mathrm{~km}$ de extensão.

As lagoas costeiras no Rio Grande do Sul, em geral, são fortemente influenciadas pelas mudanças no tempo, os quais promovem também mudanças na distribuição, quantificação e diversidade do plâncton. No que diz respeito à dinâmica da lagoa Itapeva, segundo Cardoso (2001), o vento é o seu principal agente hidrodinâmico. Durante todo o ano ocorrem ventos predominantes do quadrante SW, exceto durante o verão onde predominam ventos de NE.

Ainda de acordo com Cardoso (2001) as variáveis hidrológicas como nível da água e velocidade de fluxo, também exibem uma variação espaço-temporal intimamente relacionada com a ação do vento e com a comunidade planctônica, influenciando também na elevada turbidez do ambiente, provocado pela ressuspensão dos sedimentos. 
Figura 3. Localização da lagoa Itapeva-RS (imagem Landsat TM, de 04/02/10, cor verdadeira)
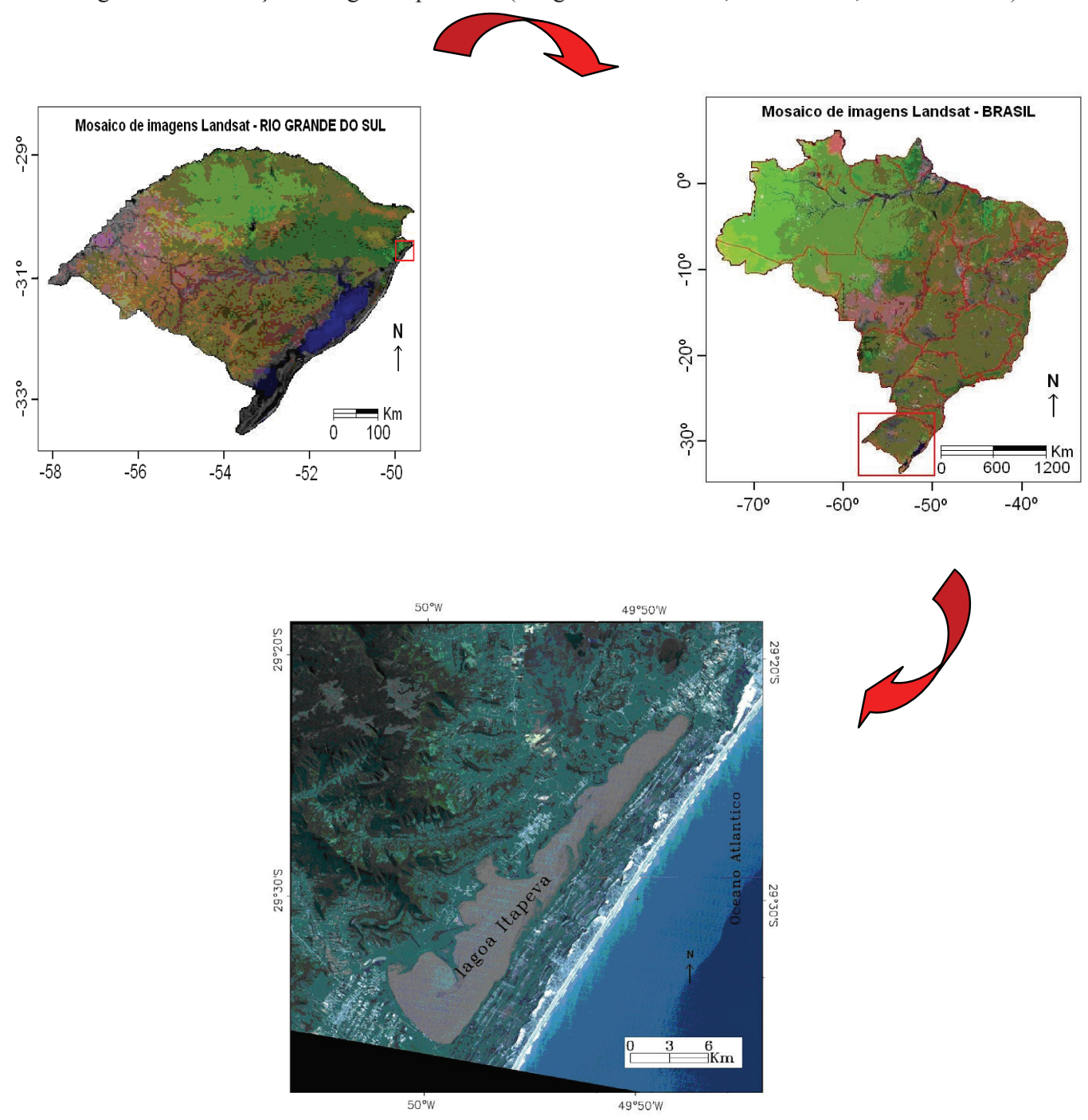

Elaboração dos autores.

\section{MATERIAIS E MÉTODOS}

Para essa análise foi adquirida uma série de 42 imagens multiespectrais do Landsat TM e ETM+ correspondentes a órbita-ponto 220-80, a partir do banco de imagens disponível no endereço eletrônico do DGI/INPE (http://www.dgi.inpe.br/CDRS).

A imagem da data 04/09/00 foi georeferenciada através de interpolação de pontos utilizando como base nas cartas da Diretoria do Serviço Geográfico de Três Cachoeiras, projeção UTM (Transversa Universal de Mercator) e Datum Córrego Alegre, na escala de 1:50.000. As demais imagens foram georeferenciadas de imagem para imagem, utilizando como base a imagem do dia 04/09/00.

Para minimizar os efeitos atmosféricos nas imagens, foi realizada a correção atmosférica, aplicando-se o método Dark Object Subtraction (DOS) desenvolvido por Chávez (1989) e a conversão dos valores para reflectância.

Posteriormente, foi gerado um polígono limite da área da lagoa Itapeva utilizado como máscara de recorte.

Após o pré-processamento das imagens, aplicou-se a equação do Índice de Vegetação por Diferença Normalizada (NDVI). A equação de NDVI (Equação 1) segundo Rouse et al (1973): 


$$
\mathrm{NDVI}=\frac{\text { IV.P. }+\mathrm{V}}{\text { IV.P. }-\mathrm{V}}
$$

onde IV.P = comprimento de onda do infravermelho próximo;

$$
\mathrm{V}=\text { comprimento de onda do vermelho. }
$$

Para a Análise de Séries Temporais (TSA) foram gerados dois arquivos: (1) de imagens organizadas de acordo com a sua data; e (2) de imagens subdivididas pelas estações do ano, para análise da sazonalidade dos padrões. Após a geração dos diagramas de TSA, foram analisadas e identificadas as imagens que obtiveram maior contribuição nas Componentes Principais (CPs).

Para as imagens de maior contribuição nas CPs foram estabelecidos intervalos de classes de NDVI, de forma a ressaltar a sua variação espacial na lagoa Itapeva.

Foi realizada uma expedição de campo no dia 18 de outubro de 2010, coincidente a data de passagem do satélite Landsat, para a coleta de amostras de água da lagoa Itapeva, com objetivo de validar os padrões observados nas imagens de NDVI. Para tanto, foram coletadas amostras de água em seis pontos amostrais para clorofila_a, Totais de Sólidos Suspensos e transparência do disco Secchi. Os resultados foram correlacionados com os valores de NDVI.

\section{RESULTADOS}

\section{Análise da variação espaço-temporal de NDVI a partir das imagens de TSA}

Para entender a variação espaço-temporal do NDVI a partir da ferramenta TSA optou-se pela análise dos diagramas resultantes e pela utilização das imagens que obtiveram maior contribuição nas $\mathrm{CP} 2 \mathrm{e}$ $\mathrm{CP} 3$, do conjunto de imagens de NDVI.

Na Figura 4, observa-se a contribuição de cada imagem de NDVI nas três primeiras Componentes Principais geradas a partir da TSA.

Figura 4. Contribuição das três primeiras Componentes Principais, geradas a partir da TSA, com base nas 42 imagens de NDVI, lagoa Itapeva-RS

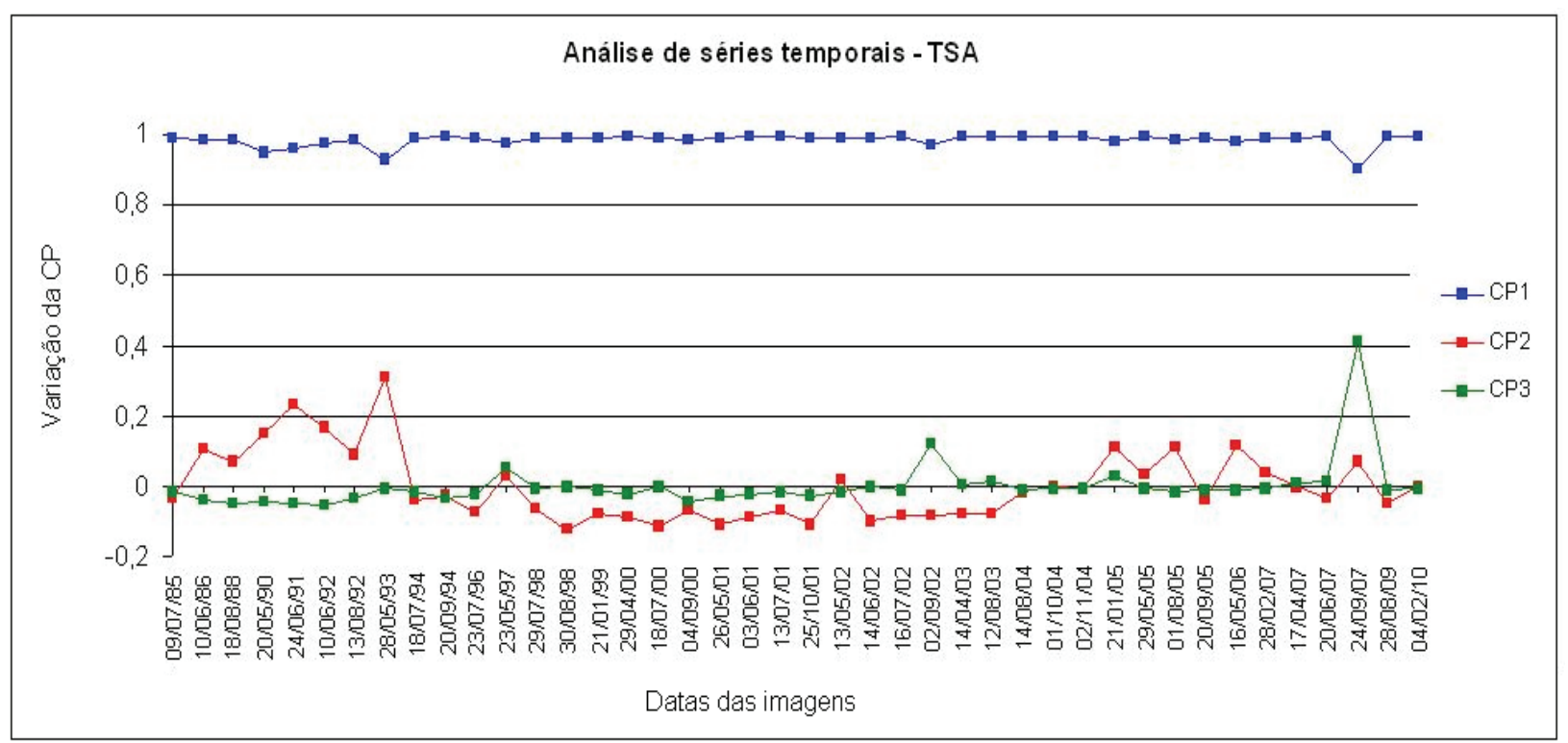

Org. dos autores. 
A partir da análise da série de imagens de NDVI e dos perfis da Figura 4, observa-se que os picos apresentados pelas $\mathrm{CP}_{2}$ e $\mathrm{CP}_{3}$ estão relacionados aos altos valores de NDVI. No entanto, durante o período de 1994 a 2004, os valores das $\mathrm{CP}_{2}$ e $\mathrm{CP}_{3}$ são baixos. Nesse período de dez anos, as imagens de NDVI apresentaram padrões na sua dinâmica muito semelhantes, podendo estar relacionada com o ciclo de desenvolvimento do fitoplâncton, a um longo período de altos índices pluviométricos, ou ainda a um período de secas.

Durante a série temporal de imagens analisada foram encontrados poucos dados pluviométricos sobre a região, ou ainda os dados disponíveis não possuem uma abrangência total dos anos analisados pela série temporal de imagens, deixando algumas lacunas em aberto sobre a pluviometria da região.

Para a análise das imagens foram estabelecidas classes de NDVI, onde os valores foram agrupados em oito (8) classes de NDVI com a finalidade de destacar a sua variação espacial na lagoa Itapeva. Foram abstraidos os intervalos que possuíam pouca representação espacial e não eram expressivos da sua dinâmica.
A Figura 5 apresenta as imagens classificadas de NDVI que obtiveram maior contribuição nas $\mathrm{CP}_{2}$ e $\mathrm{CP}_{3}$ da série temporal de imagens. As imagens referem-se ao outono (5-A) e à primavera (5-B), reforçando a idéia de que é nestas estações do ano que ocorrem as maiores variabilidades na dinâmica da lagoa Itapeva. Os elevados valores de NDVI (classes 5 e 6) encontrados na lagoa, estão associados ao período de floração do fitoplâncton.

$\mathrm{Na}$ imagem 5-A ocorre uma distribuição espacial de classes de NDVI bastante heterogênea, que pode estar associada às mudanças de direção e intensidade do vento e a circulação da água, comuns nesta estação do ano. Os ventos predominantes nesta estação são do quadrante SW-W, o que pode ocasionar o deslocamento dos organismos fitoplanctônicos, pois esses não oferecem resistência ao fluxo e podem ser carregados para a porção norte da lagoa Itapeva

$\mathrm{Na}$ imagem 5-B observa-se uma pequena variação espacial de classes de NDVI, apresentando elevados valores homogeneamente em toda a extensão da lagoa.

Figura 5. Imagens de classes de NDVI de maior contribuição nas $\mathrm{CP}_{2}$ e $\mathrm{CP}_{3}$, lagoa Itapeva-RS

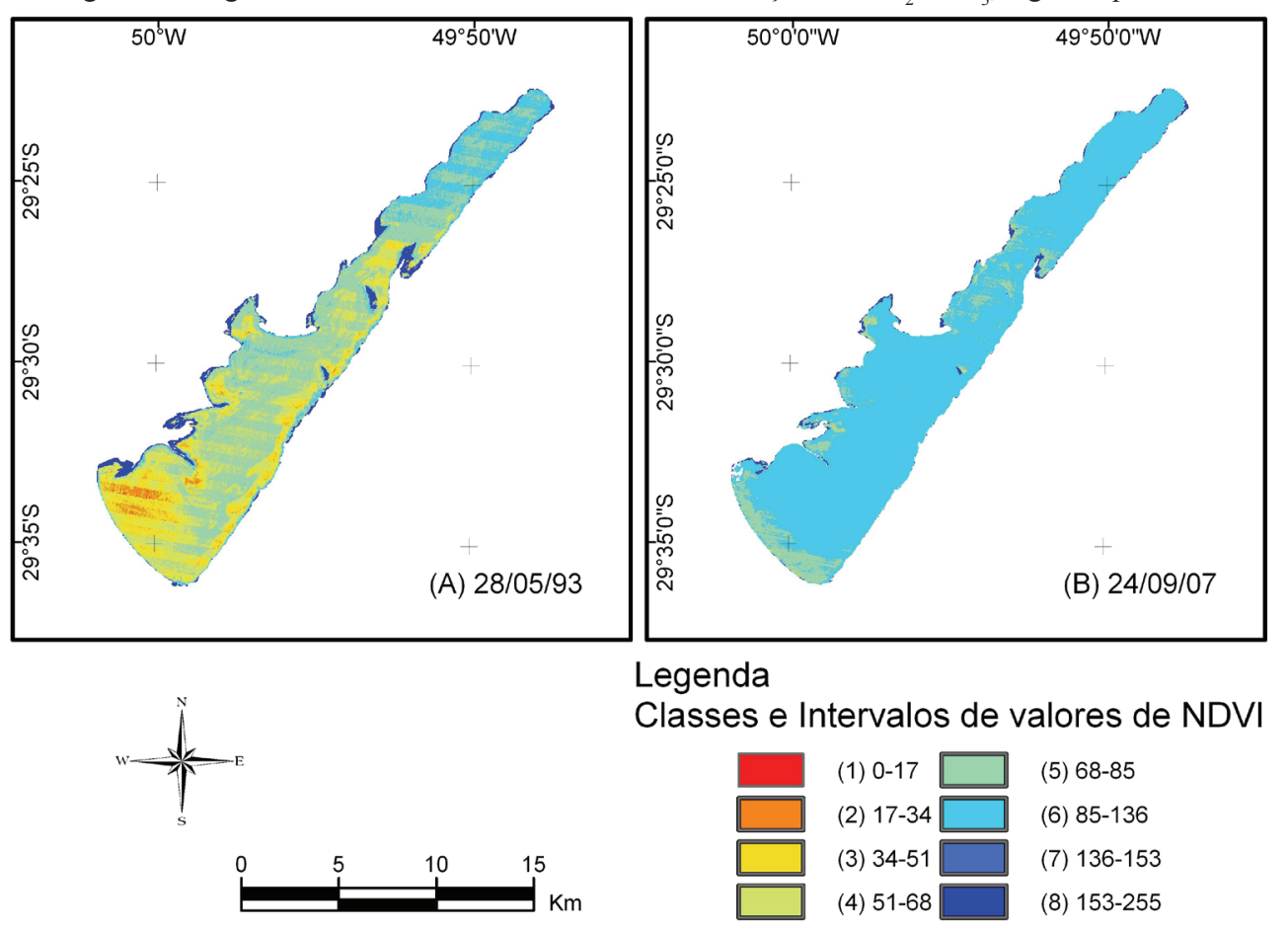

Elaboração dos autores. 


\section{Análise da variação espaço-temporal a partir das} imagens de TSA para as estações do ano

Buscando analisar se há ou não ocorrência de padrões sazonais, foi gerada uma TSA para cada uma das quatro estações do ano, gerando diagramas para as três primeiras CPs.

As imagens de NDVI que obtiveram a maior contribuição na Componente Principal $\mathrm{CP}_{2}$ foram: verão, dia 21/01/99; outono, dia 28/05/93; inverno, dia 25/10/01 e primavera, dia 24/06/91.

A Figura 6 apresenta as imagens classificadas de NDVI da lagoa Itapeva de cada estação do ano que obtiveram a maior variação espacial de classes de NDVI para a $\mathrm{CP}_{2}$ na análise das séries temporais (TSA).

A imagem 6-A corresponde ao verão. A variação espacial das classes de NDVI é baixa nesta estação do ano, ocasionada pelos pequenos volumes de precipitação, ventos fracos e de mesma direção; e período de senescência do fitoplâncton. Nota-se que a maior área da lagoa encontra-se classificada nas classes 1 e 2.

As maiores concentrações de NDVI são encontrados nos setores sul e norte da lagoa, fato que pode ser explicado pela ação dos ventos do quadrante $\mathrm{NE}$, que proporciona uma distribuição decrescente de biomassa no sentido norte-sul da lagoa. Nota-se uma variação de classes de NDVI nas áreas próximas da foz do rio Três Forquilhas e no canal de escoamento da água, que liga a foz do rio Cardoso, (representadas pelo ponto nas imagens da Figura 6) à porção sul da lagoa, ocasionada pelo aumento da turbidez e descarga de sedimentos.

Figura 6. Imagens de classes de NDVI que obtiveram maior contribuição na $\mathrm{CP}_{2}$ correspondente ao verão (a), outono (b), inverno (c) e primavera (d), lagoa Itapeva-RS.

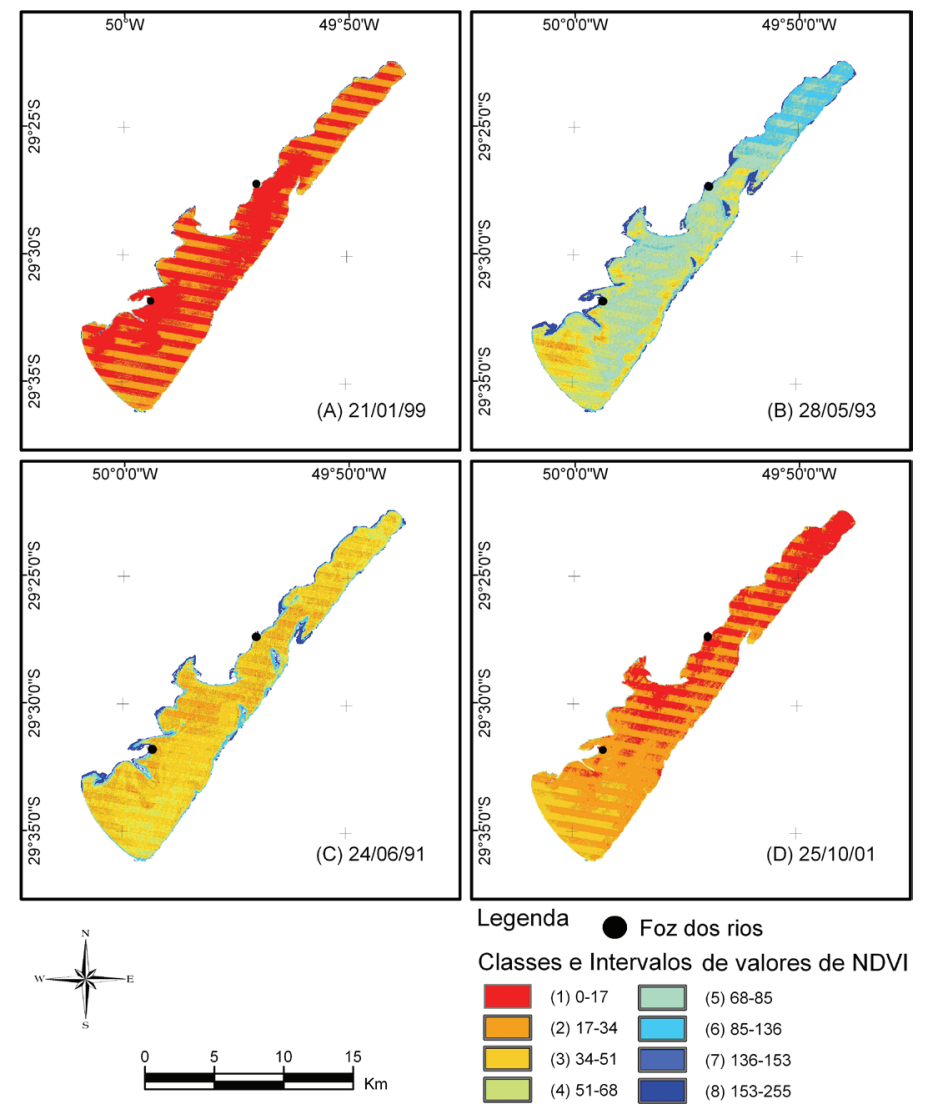

Elaboração dos autores. 
A imagem 6-B representa o comportamento característico da lagoa durante o outono. Nesta estação do ano ocorre a segunda floração de algumas espécies de fitoplâncton. Mudanças na intensidade e na direção dos ventos podem promover e propiciar a floração do fitoplâncton. Nesse período o nível de água da lagoa encontra-se baixo, deixando expostos os bancos de areia que ocorrem na região nordeste da lagoa.

Em geral, durante o outono ocorre uma distribuição decrescente de valores de NDVI no sentido norte para sul da lagoa. Como a porção norte encontra-se mais isolada da ação dos ventos e sua profundidade é menor, ocorre o maior aquecimento das águas e menor circulação destas, proporcionando um ambiente mais propenso a floração do fitoplâncton.

A imagem 6-C corresponde ao inverno. Observa-se nessa imagem que o nível de água da lagoa encontra-se baixo, o que pode estar associado a um período de estiagem.

Neste período do ano, a floração do fitoplâncton encontra-se estagnada devido às baixas temperaturas. A variabilidade espacial de NDVI é pequena em toda a extensão da lagoa, apresentando valores relativamente baixos de NDVI, nas classes 2 e 3 , predominantemente.

A imagem 6-D correspondente a primavera e mostra uma variação espacial de classes de NDVI que pode ser considerada atípica para esta estação do ano, pois apresenta baixos valores de NDVI. O que pode justificar essa variação espacial de NDVI é a ocorrência de elevados volumes de chuva.

Nota-se um decréscimo dos valores de NDVI no sentido sul norte da lagoa, ocasionada pelo transporte dos organismos fitoplanctônicos pela circulação das águas para a porção sul da lagoa, representada na imagem pelos tons de amarelo.

A Figura 7 apresenta as imagens classificadas de NDVI da lagoa Itapeva de cada estação do ano que obtiveram a maior variação espacial de classes de NDVI para a $\mathrm{CP}_{3}$ na análise das séries temporais (TSA).

Figura 7. Imagens de classes de NDVI que obtiveram maior contribuição na CP3 correspondente ao verão (a), outono (b), inverno (c) e primavera (d), lagoa Itapeva-RS

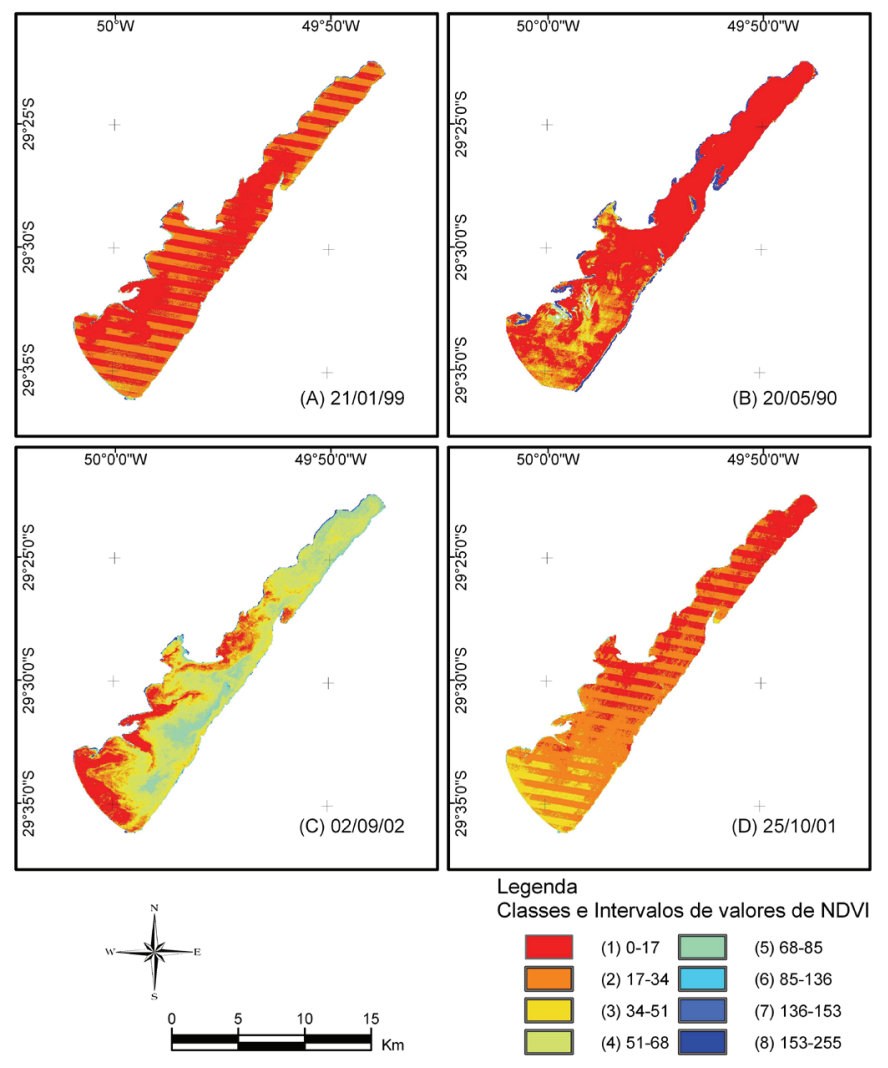

Elaboração dos autores. 
A imagem 7-A corresponde ao verão. Nesta estação do ano foi mais difícil adquirir imagens de satélite devido à ocorrência de cobertura de nuvens, o que atrapalha na obtenção de informações. Assim, a imagem 7-A corresponde a mesma imagem apresentada na 6-A. o que ocorre também com a imagem 7-D, mesma imagem da 6-D.

Durante o outono, ocorre a segunda floração de algumas espécies de fitoplâncton. No entanto, na imagem 7-B nota-se uma dinâmica diferente do padrão característico encontrado nesta época do ano. Analisando o padrão de sucessão de distribuição do NDVI na lagoa, é provável que tenham ocorrido chuvas nos dias que antecederam a data da imagem de satélite 7-B que ocasionou tal dinâmica.

Nesta imagem, a variação das classes de NDVI está associada a circulação das águas, e os organismos são arrastados para o setor sul da lagoa, onde são observadas as maiores classes de NDVI.

A imagem 7-C corresponde ao inverno e apresenta uma variação espacial de classes de NDVI diferente do padrão comumente encontrado para esta estação do ano.

De forma geral, durante o inverno, a floração do fitoplâncton encontra-se estagnada. A variação do NDVI ocorre de maneira mais homogênea em toda a extensão da lagoa, apresentando baixos valores. No entanto, a imagem de inverno em análise data do inicio do mês de setembro, período onde já se inicia a floração do fitoplâncton.
Na imagem 7-C notam-se valores elevados de NDVI. Os valores se distribuem de forma crescente no sentido sul norte. Esta distribuição é caracterizada pela ação dos ventos da direção SW, que arrastam os organismos fitoplanctônicos nesse sentido.

Observar-se um deslocamento das menores classes de NDVI, representadas pelos tons de vermelho, no sentido da margem oeste para o centro da lagoa, ocasionado pela direção dos ventos. A ação dos ventos também ocasiona uma concentração maior de organismos fitoplanctônicos na margem leste da lagoa, ocorrendo classes de NDVI alto (classe 5) nessa área.

De forma geral, observamos que se estabelece um padrão de distribuição de NDVI para cada estação do ano, relacionado ao período de floração do fitoplâncton. Outros fatores também estabelecem padrões de distribuição do NDVI, como os ventos e a chuva.

\section{Correlação dos valores de NDVI com os parâmetros coletados em campo}

Com a finalidade de validar a análise da variação de distribuição dos valores de NDVI na lagoa Itapeva a partir da ferramenta de Análise de Séries Temporais de imagens, foi realizada uma expedição de campo para coleta de dados in situ. Os resultados foram correlacionados aos valores dos pixels da imagem de NDVI da data da expedição de campo. $\mathrm{Na}$ Figura 8 são apresentados os pontos de coleta das amostras de água na lagoa Itapeva.

Figura 8. Imagem de NDVI em nível de cinza (18/10/10) e pontos de coleta das amostras, lagoa Itapeva-RS.

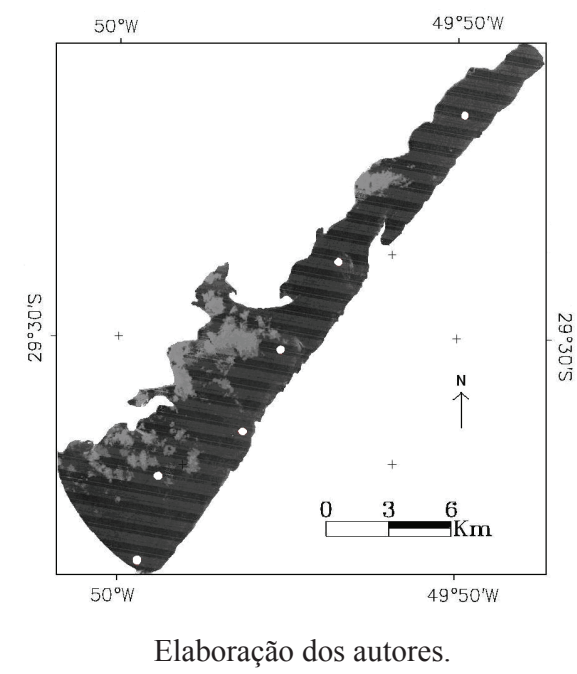

Soc. \& Nat., Uberlândia, 25 (2): 427-440, mai/ago/2013 
A Tabela 1 apresenta os dados de concentração de clorofila_a, de Totais de Sólidos em Suspensão e de transparência do disco de
Secchi obtidos na coleta do dia 18/10/10, na lagoa Itapeva, e os valores médios dos pixels de NDVI.

Tabela 1. Resultados das amostras coletadas em 18/10/2010, lagoa Itapeva - RS.

\begin{tabular}{c|c|c|c|c}
\hline Pontos de coleta & Sólidos Totais (mg/L) & Clorofila_a (ug/L) & Disco de Secchi (cm) & $\begin{array}{c}\text { Valor médio dos } \\
\text { pixels }\end{array}$ \\
\hline 1 & 46 & 3,37 & 42 & $-0,397787$ \\
\hline 2 & 106 & ND & 26 & $-0,489904$ \\
\hline 4 & 111 & 15,63 & 32 & $-0,402215$ \\
\hline 5 & 87 & 14,4 & 29 & $-0,456952$ \\
\hline 6 & 47 & 4,84 & 49 & $-0,407884$ \\
\hline 7 & 67 & 3,45 & 35 & $-0,448613$ \\
\hline
\end{tabular}

Org. dos autores.

A partir dos resultados apresentados na Tabela 1, observa-se que a transparência da água está diretamente associada a turbulência da água e quantidade de Totais de Sólidos em Suspensão. Esses resultados mostram que quando ocorre aumento dos Totais de Sólidos em Suspensão, a transparência diminui, e vice-versa.

Os maiores valores de transparência encontrados na lagoa Itapeva foram 42 e 49 centímetros de profundidade. Esses valores são compatíveis com os encontrados por Pereira et al. (2007) em lagoas costeiras do Rio Grande do Sul, como as lagoas Caieira e Palmital.

Os resultados referentes a concentração de clorofila_a apresentaram baixos valores de concentração na lagoa Itapeva nesta data, com valores abaixo de $16 \mathrm{ug} / \mathrm{L}$, assim como os resultados encontrados para os Totais de Sólidos Suspensos (TSS), abaixo de $111 \mathrm{mg} / \mathrm{L}$.

No entanto, mesmo que a lagoa Itapeva te- nha apresentado baixos valores de concentração de clorofila_a, a variação espacial e temporal de classes de NDVI apresentou bom desempenho na visualização da dinâmica da lagoa e para o estabelecimento de padrões de distribuição de clorofila_a.

Observa-se na Tabela 1, que os valores de concentração de clorofila_a obtidos foram baixos em alguns pontos. No ponto 2, por exemplo, na análise de laboratório não foram detectados níveis de clorofila a.

Por se tratar de uma lagoa costeira, a lagoa Itapeva apresenta uma dinâmica intimamente associada a ação dos ventos e as baixas profundidades. Ocorrem baixas concentrações de NDVI durante a maior parte do ano, ocorrendo valores mais elevados apenas nos períodos de floração, como na primavera, e às vezes durante o outono, quando ocorre a segunda floração de algumas espécies de fitoplâncton.

Na Tabela 2 são apresentadas as correlações de Pearson $(r)$ entre as variáveis em estudo na lagoa Itapeva.

Tabela 2. Matriz de correlações estabelecidas entre as variáveis analisadas,

lagoa Itapeva-RS

\begin{tabular}{c|c|c|c|c}
\hline $\begin{array}{c}\text { Correlação dos parâ- } \\
\text { metros (r) }\end{array}$ & TSS & Disco de Secchi & $\begin{array}{c}\text { Valores dos pixels de } \\
\text { NDVI }\end{array}$ & Clorofila_a \\
\hline TSS & $\mathrm{r}=1$ & $\mathrm{r}=1$ & & \\
\hline Disco de Secchi & $\mathrm{r}=-0,8665$ & $\mathrm{r}=0,7308$ & $\mathrm{r}=1$ & \\
\hline $\begin{array}{c}\text { Valores dos pixels } \\
\text { de NDVI }\end{array}$ & $\mathrm{r}=-0,4793$ & $\mathrm{r}=-0,7156$ & $\mathrm{r}=-0,1567$ & $\mathrm{r}=1$ \\
\hline Clorofila_a & $\mathrm{r}=0,9059$ & & \\
\hline
\end{tabular}

Org. dos autores. 
Variação do Índice de Vegetação por Diferença Normalizada na lagoa Itapeva, litoral norte do Rio Grande do Sul, Brasil, a partir de análise de séries temporais

Juliane Beatriz Lissner, Laurindo Antonio Guasselli

Na Tabela 3 são apresentados os níveis de variáveis analisadas na lagoa Itapeva. confiança entre as correlações estabelecidas entre as

Tabela 3. Matriz dos níveis de confiança das correlações estabelecidas entre as variáveis, lagoa Itapeva-RS

\begin{tabular}{c|c|c|c|c}
\hline $\begin{array}{c}\text { Nível de confiança } \\
\left(\mathrm{r}^{2}\right)\end{array}$ & TSS & Disco de Secchi & $\begin{array}{c}\text { Valores dos pixels de } \\
\text { NDVI }\end{array}$ & Clorofila_a \\
\hline TSS & $\mathrm{r}^{2}=1$ & & & \\
\hline Disco de Secchi & $\mathrm{r}^{2}=0,75$ & $\mathrm{r}^{2}=1$ & & \\
\hline $\begin{array}{c}\text { Valores dos pixels } \\
\text { de NDVI }\end{array}$ & $\mathrm{r}^{2}=0,23$ & $\mathrm{r}^{2}=0,53$ & $\mathrm{r}^{2}=1$ & $\mathrm{r}^{2}=1$ \\
\hline Clorofila_a & $\mathrm{r}^{2}=0,82$ & $\mathrm{r}^{2}=0,51$ & $\mathrm{r}^{2}=0,02$ & \\
\hline
\end{tabular}

Org. dos autores.

As correlações mais significativas para os parâmetros analisados nesta data foram estabelecidas entre os Totais de Sólidos Suspensos e a clorofila_a, e os Totais de Sólidos Suspensos e a transparência do disco de Secchi.

A correlação obtida através dos dados de concentração de clorofila_a da lagoa Itapeva e dos valores médios de NDVI, de uma janela de $3 \times 3$ pixels da imagem de satélite, obteve correlação de $r=-0,1$. A correlação estabelecida entre essas variáveis não foi significativa estabelecendo um nível de confiança menor que $0,2 \%$.

A baixa correlação entre clorofila_a e NDVI mostra que outros parâmetros devem ser levados em consideração para um melhor entendimento da dinâmica da lagoa Itapeva. É claro que um fator limitante para essa correlação foi a realização de apenas uma coleta in situ (18/10/2010), e isso se mostrou pouco significativo estatisticamente.

Entretanto, o objetivo geral da pesquisa foi o de analisar a distribuição espaço-temporal de NDVI a partir de uma série temporal de quarenta e duas (42) imagens de satélite, ficando claro que as ferramentas de TSA e NDVI demonstram potencial e eficácia. O uso dessas ferramentas propiciou o estabelecimento de padrões recorrentes de distribuição, destacando a ocorrência dos padrões sazonais.

Ao analisar diversas lagoas costeiras do Rio Grande do Sul, Pereira et al. (2007) também não encontrou correlações significativas para as variáveis de clorofila_a e reflectância da superfície. As correlações negativas entre essas variáveis foram de $-0,01$ e $-0,02$. Os autores atribuíram a falta de correlação entre os dados às imagens de satélite e as possíveis falhas no sistema de operação do satélite CBERS utilizado neste trabalho.

Pereira (1993) encontrou baixos valores de concentração de clorofila-a em seu estudo, no entanto, estabeleceu correlações entre a resposta espectral do sensor Landsat e a concentração de clorofila_a e feofitina, obtendo uma correlação positiva de 0,48 .

Já as correlações estabelecidas entre as variáveis clorofila_a e TSS foi altamente significativa $(r=$ $0,9)$ correspondendo a um nível de confiança de $82,1 \%$ da variância $\left(r^{2}=0,82\right)$ da clorofila_a explicada. Embora estas variáveis tenham apresentado correlações significativas, o aumento da quantidade de Sólidos Totais em Suspensão na água pode ter sido ocasionado pela ação de ressuspensão dos sedimentos do fundo da lagoa e aumento da disponibilidade de nutrientes para os organismos fitoplanctônicos.

A transparência do disco de Secchi e os Totais de Sólidos em Suspensão apresentaram correlação negativa $(r=-0,82)$, correspondendo a $75 \%\left(r^{2}=0,75\right)$ a variância explicada, conforme a tabela 12 .

\section{CONSIDERAÇÕES FINAIS}

É complexo estabelecer padrões para a distribuição sazonal do NDVI na lagoa Itapeva. Isso pode estar associado a picos inesperados de espécies dominantes ou raras de fitoplâncton que podem alterar 
o comportamento predominante na lagoa, e a presença de baixas concentrações de clorofila_a e de Totais de Sólidos Suspensos.

A baixa correlação entre a clorofila_a e o NDVI mostrou que outros parâmetros devem ser levados em consideração para um melhor entendimento da dinâmica da lagoa Itapeva. É claro que um fator limitante para essa correlação foi a de ter sido realizado apenas uma coleta in situ (18/10/2010), e isso se mostrou pouco significativo estatisticamente.

De acordo com os objetivos da pesquisa, entretanto, que é o de analisar a distribuição espaço-temporal de NDVI a partir de uma série temporal de quarenta e duas (42) imagens de satélite, fica claro que as ferramentas de TSA e NDVI demonstram potencial e eficácia. O uso dessas ferramentas propiciou o estabelecimento de padrões recorrentes de distribuição, destacando a ocorrência dos padrões sazonais.

A utilização da ferramenta de Análise de Séries Temporais (TSA) foi de extrema importância para a compreensão da dinâmica espaço-temporal da lagoa Itapeva possibilitando estabelecer padrões que se repetem temporalmente e sazonalmente.

\section{REFERÊNCIAS}

ARRAUT, E. M.; RUDORFF, C. de M. et al. Estudo do comportamento espectral da clorofila e dos sólidos em suspensão nas águas do lago grande de Curuai (Pará), na época da seca, através de técnicas de espectroscopia de campo. In: XII SIMPÓSIO BRASILEIRO DE SENSORIAMENTO REMOTO. 2005. Anais..., INPE, p.2447-2456, 2005.

BECKER, V. Variação da estrutura e da biomassa fitoplanctônica na Lagoa Itapeva (litoral norte do Rio Grande do Sul) em função da hidrodinâmica. 2002. Dissertação (Mestrado em Ecologia). Universidade Federal do Rio Grande do Sul, Porto Alegre, 2002. $125 \mathrm{p}$.

CARDOSO, L, 2001, Variações da estrutura planctônica da lagoa Itapeva (Sistema Lagunar Costeiro do Rio Grande do Sul) em função da hidrodinâmica. Tese (Doutorado em Engenharia de Recursos Hídricos e Saneamento Básico), IPH/UFRGS, Porto Alegre, 466p.
CHÁVEZ, P. Radiometric calibration of Landsat Thematic Mapper multispectral images. Photogrammetric Engineering and Remote Sensing. v.55, p.1285-1294, 1989.

DGI/INPE. Divisão de Geração de Imagens (sítio na internet). Disponível em : <http://www.dgi.inpe.br/ CDRS>. Acesso em: mar.2010.

LONDE, L. R.; Novo, E. M. L. M.; Calijuri, M. C. Avanços no estudo do comportamento espectral do fitoplâncton e identificação remota de algas. In: XII SIMPÓSIO BRASILEIRO DE SENSORIAMENTO REMOTO. Anais..., INPE, p. 389-396. 2005.

LOPARDO, N. Estudo hidrodinâmica e correlação com sólidos suspensos e turbidez na Lagoa Itapeva do Litoral Norte do Estado do Rio Grande do Sul. 2002. Dissertação (Mestrado em Engenharia de Recursos Hídricos e Saneamento Básico) - Universidade Federal do Rio Grande do Sul, Porto Alegre, 2002. 186p.

MARTINI, L. C. P.; Mattos, D. S.; Barbosa, D. F. P.; Rech, A. L. B. Uso de sensoriamento remoto orbital para avaliação da distribuição espacial de Clorofila_a na Lagoa da Conceição - Florianópolis, SC. Engenharia Sanitária e Ambiental, v.11, n. 4, p. 318-324, 2006.

PEREIRA, R.; SCHÄFER, A. E. et al. Aplicabilidade de métodos de Sensoriamento Remoto na avaliação e monitoramento do estado trófico de lagoas costeiras do Rio Grande do Sul (RS). In: XIII SIMPÓSIO BRASILEIRO DE SENSORIAMENTO REMOTO. Anais..., INPE, p. 3513-3520. 2007.

ROUSE, J. W.; HASS, JR., R. H.; SCHELL, J. A.; DERRING, D. W. Monitoring the vernal advancement and retrogradation (green wave effect) of natural vegetation. Prog. Rep. RSC 1978-1, Remote Sensing Center, Texas A\&M Univ., College Station, 1973. 93p.

TOMAZELLI, L. J. Contribuição ao estudo dos sistemas deposicionais Holocênicos do nordeste da província costeira do Rio Grande do Sul - com ênfase no sistema eólico. 1990. Tese (Doutorado em Geociências). Universidade Federal do Rio Grande do Sul, Porto Alegre, 1990. 
Juliane Beatriz Lissner, Laurindo Antonio Guasselli

Tomazelli, L. J. \& Villwock, J. A. Geologia do Sistema Lagunar Holocênico do Litoral do Rio grande do Sul. Pesquisas, v.18, n. 1, p.113-124. 1991.

\section{AGRADECIMENTOS}

À Universidade Federal do Rio Grande do Sul (UFRGS), ao Centro Estadual de Pesquisas em Sensoriamento Remoto e Meteorologia (CEPSRM), e à Coordenação de Aperfeiçoamento de Pessoal de Nível Superior (CAPES) pela oportunidade de bolsa de estudos, pelo auxilio e apoio financeiro. 